\title{
Quercetin in Cancer Treatment, Alone or in Combination with Conventional Therapeutics?
}

\author{
Ana Filipa Brito ${ }^{1,2,3}$, Marina Ribeiro ${ }^{1,4}$, Ana Margarida Abrantes ${ }^{1,2,3,}$, Ana Salomé Pires ${ }^{1,3,4}$, \\ Ricardo Jorge Teixo ${ }^{1}$, José Guilherme Tralhão ${ }^{1,2,5}$ and Maria Filomena Botelho, ${ }^{1,2,3}$
}

\author{
${ }^{1}$ Biophysics Unit, Faculty of Medicine, University of Coimbra, Coimbra, Portugal; ${ }^{2}$ Center of \\ Investigation on Environmental, Genetics and Oncobiology (CIMAGO), Coimbra, Portugal; \\ ${ }^{3}$ CNC.IBILI, Faculty of Medicine, University of Coimbra, Coimbra, Portugal; ${ }^{4}$ Faculty of \\ Sciences and Technology, University of Coimbra, Coimbra, Portugal; ${ }^{5}$ Surgical Department \\ A, CHUC, Coimbra, Portugal
}

\begin{abstract}
Cancer is a problem of global importance, since the incidence is increasing worldwide and therapeutic options are generally limited. Thus, it becomes imperative to find new therapeutic targets as well as new molecules with therapeutic potential for tumors. Fla-

M. Filomena Botelho vonoids are polyphenolic compounds that may be potential therapeutic agents. Several studies have shown that these compounds have a higher anticancer potential. Among the flavonoids in the human diet, quercetin is one of the most important. In the last decades, several anticancer properties of quercetin have been described, such as cell signaling, pro-apoptotic, anti-proliferative and anti-oxidant effects, growth suppression. In fact, it is now well known that quercetin has diverse biological effects, inhibiting multiple enzymes involved in cell proliferation, as well as, in signal transduction pathways. On the other hand, there are also studies reporting potential synergistic effects when combined quercetin with chemotherapeutic agents or radiotherapy. In fact, several studies which aim to explore the anticancer potential of these combined treatments have already been published, the majority with promising results. Actually it is well known that quercetin can act on the chemosensitization and radiosensitization but also as chemoprotective and radioprotective, protecting normal cells of the side effects that results from chemotherapy and radiotherapy, which obviously provides notable advantages in their use in anticancer treatment. Thus, all these data indicate that quercetin may have a key role in anticancer treatment. In this context, this review is focused on the relationship between flavonoids and cancer, with special emphasis on the role of quercetin.
\end{abstract}

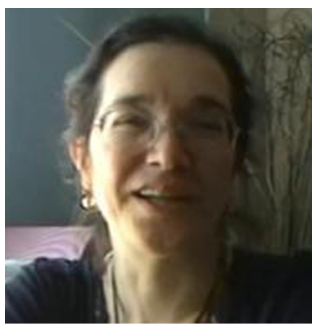

Keywords: Cancer, flavonoids, flavonols, quercetin, synergism, therapeutics.

\section{FLAVONOIDS}

Flavonoids are polyphenolic compounds present in plant-derived foods, including tea, fruits, vegetables and beverages, among others [1]. Currently it is recognized that these compounds exhibit several biological effects on human health. Namely the ability to reduce the risk of chronic pathologies, like cardiovascular diseases and cancer [2]. In fact, globally, it is known that Asians have a diet rich in fruits, vegetables and tea and that there is a significantly reduced risk of developing breast or prostate cancer in this population compared

\footnotetext{
*Address correspondence to these author at the Biophysics UnitFaculty of Medicine, University of Coimbra, Pólo III - Pólo das Ciências da Saúde, Azinhaga de Santa Comba, Celas, 3000-548 Coimbra, Portugal; Tel: +351239480200; Fax: +351239480217; E-mails: mabrantes@fmed.uc.pt; mfbotelho@fmed.uc.pk
}

with western populations [3]. These data introduce an interesting observation: flavonoids can act as natural chemopreventive and chemotherapeutic agents. In this context, the anti-cancer effect of flavonoids have been studied with the aim of inducing apoptosis and inhibiting cell growth in several types of tumors $[1,2,4]$.

In addition to these characteristics, other biological activities of flavonoids include anti-oxidant, anti- inflammatory, antimicrobial, hepatoprotective, antidiabetic, anti-allergic, antithrombotic, antiviral, cardioprotective and anti-bacterial [3]. These biological actions arise as a result of changes in the activity of several intracellular enzymes, including tyrosine kinases, protein kinase $\mathrm{C}$ (PKC), the phosphatidylinositol 3-kinase (PI3K) and mitogen activated protein kinases (MAPK). Several studies have also demonstrated that flavonoids 
may alter the glucose uptake stimulated for insulin through receptor tyrosine kinase (RTK) and/or via PI3K activity modulation in muscle or adipose tissue cells $[1,2,4-6]$. In fact, several studies have also demonstrated that flavonoids, namely the non-glycosilated forms (aglycones), induce an inhibitory effect on glucose uptake by cells, showing thereby that flavonoids may be used, in vitro, as blockers of glucose uptake [1, $2]$.

The flavonoids basic structure (Fig. 1) is characterized by the presence of two benzene rings (rings $\mathrm{A}$ and B) linked through a heterocyclic ring that contains oxygen (ring C) $[1,2,4]$. According to the level of oxidation and the substitution patterns of this primary structure, flavonoids can be classified in flavones, flavonols, flavonones, isoflavones, anthocyanins and catechins (Fig. 2) [4].

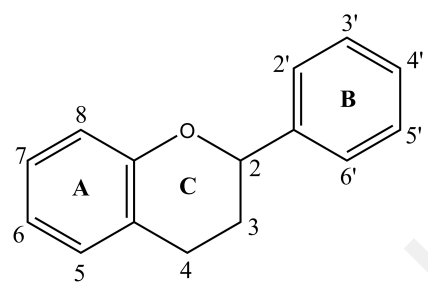

Fig. (1). Basic structure of flavonoids. The basic structure of flavonoids consists in two benzene rings (rings A and B) linked through a heterocyclic ring containing oxygen (ring C).

The flavonoids are able to interact in many cellular and/or molecular functions using, for that, different mechanisms of action. As mentioned above, it is known that flavonoids and isoflavonoids inhibit glucose influx $[9,10]$. In this context, it has been studied the action of these substances as competitive inhibitors of glucose transporter 1 (GLUT-1) [1-14]. This glucose transporter has three ATP binding domains that are essential for its conformation and affinity. In this way, these ATP binding sites appear to be a possible target for pharmacological strategies that result in GLUT-1 blocking. Currently, it has been demonstrated that flavonoids such as genistein and quercetin, inhibit ATP binding tyrosine kinases and also have the ability to competitively inhibit GLUT-1 through this mechanism [11]. In fact, the effects of flavonoids on glucose absorption and digestion has been the subject of several studies [15-18]. The inhibitory effect of flavonoids on glucose uptake appears to be already well established, so these compounds have even been suggested for the treatment of diabetes [19-21]. In 2011, Pereira [19] and colleagues demonstrated that quercetin reduced the effect of sucrase and maltase in in vitro and in vivo models. More recently, a study in an animal model of diabetes mellitus showed that the oral administration of quercetin $(100 \mathrm{mg} / \mathrm{kg})$ decreased incremental plasma glucose levels 30-180 min after a single oral dose of starch and the area under the postprandial glucose response, comparing to the control group [22].

On the other hand, several flavonoids, such as quercetin, have been described as inhibitors of tyrosine kinase activity. This flavonol inhibits the tyrosinic kinase activity of proto-oncogene protein $60\left(\mathrm{pp} 60^{\mathrm{v}-\mathrm{src}}\right)$, also promotes the inhibition of protein kinase activity cAMP-independent, protein kinase $\mathrm{C}$ (PKC) $\mathrm{Ca}^{2+} /$ phospholipid dependent, phosphorylase kinase and $\mathrm{Na}^{+} / \mathrm{K}^{+}$-ATPase and $\mathrm{Ca}^{2+} / \mathrm{Mg}^{2+}$-ATPase pumps $[23,24]$. It is known that the tyrosinic activity specific of kinase protein is associated with oncogenic products of $\operatorname{src}$ retroviral gene family, as well with the role of retroviruses in cellular transformation process. It was found that in mutant proteins with reduced tyrosine kinase activity the cellular transformation efficiency is
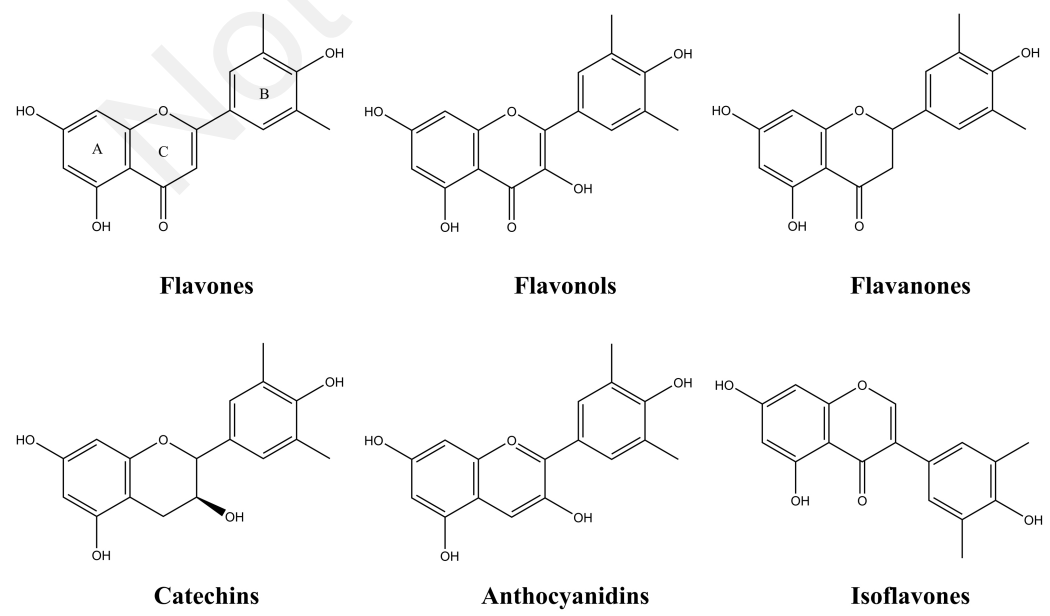

Fig. (2). Flavonoids sub-classes. The classification of these flavonoids subclasses is based on variations in heterocyclic $\mathrm{C}$ ring. 
lower, while in mutant proteins that don't have this type of activity, the cellular transformation already becomes incomplete. Taking into account the key role that tyrosinic phosphorylation has in cell proliferation and cell transformation a tyrosine kinase specific inhibitor, like flavonoids, can be considered an antitumor agent, constituting an essential tool for understanding the physiological role of its phosphorylation in cancer progression [23, 24].

\section{QUERCETIN}

Quercetin [2-phenyl-4H-1-benzopyran-4-one, 2phenylchromone] is a bioactive flavonoid, flavonol class, whose the main dietary sources are fruits and vegetables such onions, apples and berries. This flavonoid shows anti-oxidant, anti-inflammatory and vasodilator effects, being proposed as a potential anticancer agent. Epidemiological studies revealed that the daily intake per individual of quercetin in the United States, Europe and Asia ranges from 4 to $68 \mathrm{mg}$ [23, $25,26]$.

The empirical formula of quercetin is $\mathrm{C}_{15} \mathrm{H}_{10} \mathrm{O}_{2}$ (Fig. 3 ) and its molecular weight is $302.24 \mathrm{~g} / \mathrm{mol}$ [23].

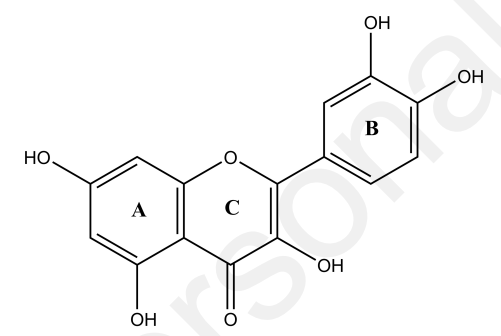

Fig. (3). Quercetin molecular structure.

Quercetin is present in the diet, mostly in its glycosylated form, where glycosidic bonds link the sugar and the phenolic groups [23, 27].

Analyzing the structure-activity relationship of quercetin it appears that its chemical structure defines its physical properties. Quercetin has available three possible sites for chelation: catechol $>\alpha-$ hydroxycarbonyl $>\beta$-hydroxycarbonyl. This property allows quercetin to participate in complex reactions, neutralizing different reactive oxygen species, chelating transition metal ions and inhibiting enzymes activity. Quercetin has structural elements responsible for its antioxidant activity, in particular, three hydroxyl groups attached to the heterocyclic ring and two to the ring B. The substitution of these hydroxyl groups, namely carbons 3 and 5 of rings B and A, respectively, gives it a good reactivity against free radicals, that it also responsible for the high anti-proliferative potential of quercetin $[23,24]$.
Currently, quercetin pharmacokinetics is not yet fully understood [23, 24, 28, 29]. Nevertheless, it is known that quercetin and its glycosides obtained from the diet are absorbed along the gastrointestinal tract, being hydrolyzed to aglycones by colonic microflora and, subsequently, transported into epithelial cells by simple diffusion depending on lipophilicity. Another quercetin glycosides absorption pathway is through sodium-dependent glucose transporter-1 (SGLT-1), being often hydrolyzed by intracellular $\beta$-glucosidases. The absorption can be followed by excretion into the lumen through the multidrug resistance-associated protein-2 (MRP-2). Quercetin absorbed in the mucosa is converted, mostly in conjugated metabolites that are transported into the circulatory system [23, 24, 28, 29].

Regarding its biodistribution, de Boer and coworkers ascertained the quercetin availability to rats and pigs tissues, showing that high concentrations of this compound were found in lungs, kidneys, heart and liver. The authors also found quercetin methylated derivatives in lung. Concerning quercetin excretion, the major route of elimination of a substantial part of its metabolites in humans and rats is made by the bile [23, $26,30]$.

\section{QUERCETIN ANTI-CANCER PROPERTIES}

According with data already published, it is extremely important to enhance the anticancer properties of quercetin. Several in vitro and in vivo studies have shown that quercetin has activity against many kinds of tumor cells, which may be due to its anti/pro-oxidant and anti-inflammatory properties, and also to other mechanisms of action less explored [4, 25, 26, 31-33]. Among the least explored anticancer effects of quercetin one can highlight its role as GLUT-1 inhibitor [14], a competitive inhibitor of the efflux pumps [24, 34] and their ability to block the cell cycle in several phases [1, 35] (Fig. 4). In summary, it is known that quercetin can slow the growth of tumor cells and promote apoptosis, which makes this flavonol a promising compound in the prevention and treatment of cancer $[4$, $26,31]$.

\section{QUERCETIN EFFECT ON CELL PROLIFERA- TION AND SIGNAL TRANSDUCTION}

In molecular terms, several in vitro studies demonstrated that quercetin has diverse biological effects, inhibiting multiple enzymes involved in cell proliferation, as well as, in signal transduction pathways. So, quercetin interferes with different proteins such as PKC, cdc25 phosphatase, PI3K, protein kinase B phos- 


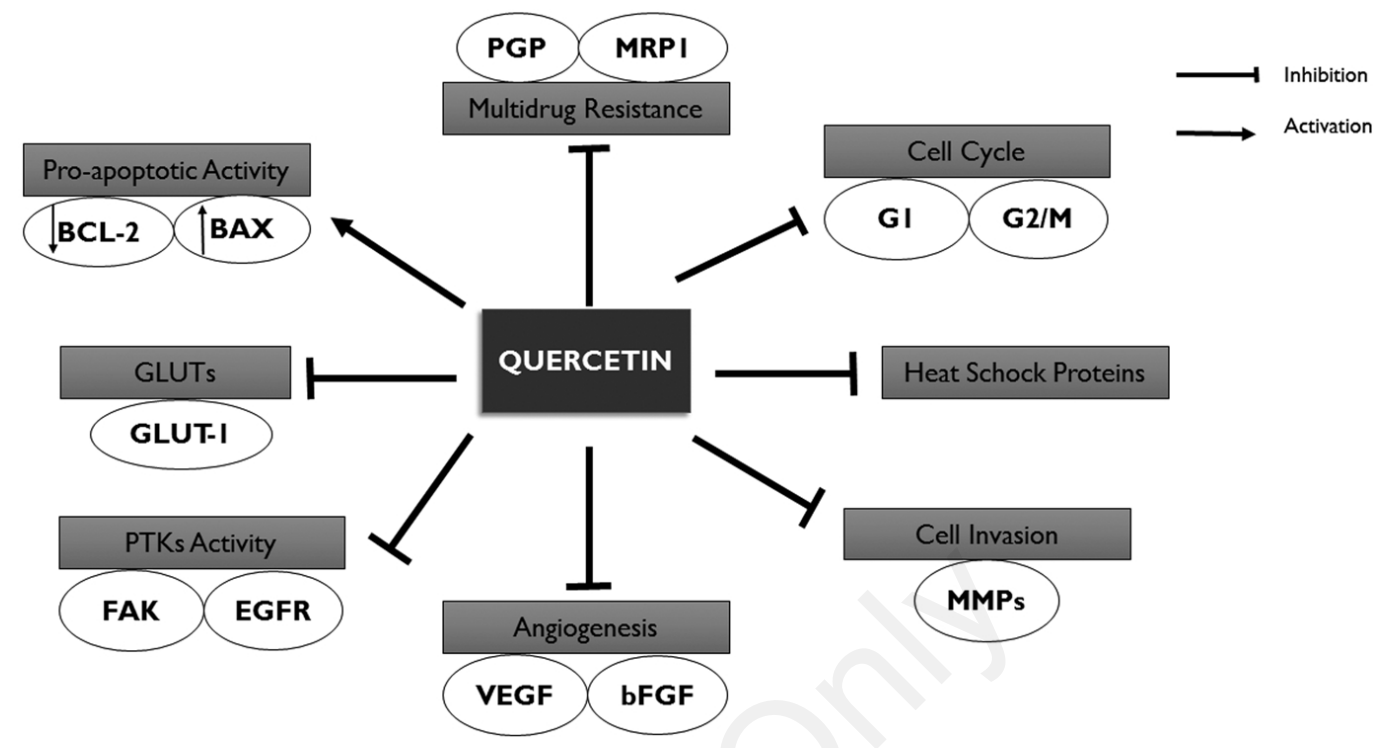

Fig. (4). Schematic representation of quercetin action in cancer cells. Quercetin has been described as a possible new anticancer drug. Quercetin can act as an inhibitor of multidrug resistance key proteins such as PGP and MRP1 as well as an inhibitor of cell cycle, inducing cell blocking in G1 and G2/M. Anticancer activity of quercetin is also reported by its pro-apoptotic activity by inducing increased the expression of pró-apoptotic proteins of BCL-2 family, like BAX and decreased the expression of the anti-apoptotic proteins of the same family like BCL-2, anti-angiogenesis effect by blocking VEGF and bFGF expression and by inhibiting cell invasion by suppression of MMPs activity. Quercetin can also interfere in different signaling pathways, namely by inactivating some proteins with tyrosine kinase activity, such as FAK and EGFR. Quercetin can also influence glucose metabolism by inhibiting glucose transporters, namely GLUT-1. It was also found that quercetin inhibit the production of heat schock proteins in different types of cancer.

phorylated (P-Akt), DNA topoisomerase II and Nterminal kinase c-Jun (JNK). In addition to those mentioned, quercetin also revealed the ability to inhibit the expression of the mutated P53, leading to a blockade of the cell cycle in the G2-M phase [35]. Quercetin has also the potential to inhibit the function and expression of the androgen receptor as demonstrated in a study in prostate tumor cells [36]. Also in pancreatic tumors it was demonstrated the ability of quercetin of blocking the activity of tyrosine kinase of epidermal growth factor receptor (EGFR) [26, 37].

Tyrosine kinases (PTKs) may be involved in various steps in tumor development, such as progression, metastasis and angiogenesis [3]. In general, the loss of PTK regulatory mechanisms are involved in the growth of neoplastic lesions. In turn, the down-regulation of specific PTKs, could impair the tumoral growth $[3,38]$. Quercetin possesses the ability to modulate the activity of several cellular protein PTKs which might have many implications in protection against cancer, and this is one of the lines of action of this polyphenol as anticancer agent $[3,38,39]$. Among PTKs, the role of focal adhesion kinase (FAK) and EGFR in the regulation of tumor cells growth has been the subject of extensive research $[3,38,40]$. In 2005, Lee and co-authors dem- onstrated, in a pancreas cancer cell line (MiaPaCa-2), that FAK activity can be suppressed by quercetin [41] On the other hand, Huang and colleagues had previously verified, in skin cancer cells, that quercetin significantly inhibit the phosphorylation of cellular proteins, like EGFR [42]. Also Huang and colleagues have demonstrated that quercetin is a potent PTK inhibitor. In their work, in pancreas cancer cells, they demonstrate that quercetin inactivated the tyrosine kinase activity of EGFR and induced apoptosis. In this study, quercetin also supresses the FAK expression. In summary, this study demonstrated that quercetin reduced the phosphorylated FAK levels and blocked the EGFRsignaling pathway, suppressing tumor cells migration and invasive potential, and inhibiting cell growth [38]. In turn, in Sprague Dawley rats, Firdous and colleagues demonstrated that the intake of $200 \mathrm{mg}$ of quercetin per $\mathrm{kg}$ body weight, through oral gavage, thrice a week during 16 weeks was effective in preventing prostate cancer progression through EGFR signaling pathway inhibition [43].

\section{QUERCETIN EFFECT ON CELL CYCLE}

Regarding the effect on cell cycle, it is known that in different types of tumor cells the treatment with 
quercetin causes stops in cell cycle at $\mathrm{G} 2 / \mathrm{M}$ phase or G1 phase $[1,35]$. It is also known that the expression of surviving, an apoptosis protein inhibitor, varies throughout the cell cycle, in response to quercetin, in a dependent manner. Thus, in response to this compound, the survivin expression increases in $\mathrm{G} 2 / \mathrm{M}$ phase and decreases, then in G1 phase. The survivin expression is regulated through the treatment with quercetin, from the activation of extracellular signal-regulated kinase (ERK) by $\mathrm{H} 3$ histone deacetylation. Quercetin activates the histone deacetylase enzyme which reduces the acetylation of $\mathrm{H} 3$ histone [36]. Also in a myelomonocytic leukemia xenograft, Maso and colleagues demonstrated that the intraperitoneal injection of $120 \mathrm{mg} / \mathrm{kg}$ of quercetin once every four days induced cell cycle arrest in G1 phase of cell cycle [44].

\section{QUERCETIN PRO-APOPTOTIC ACTIVITY}

Apoptosis mediated through quercetin may result from proteic stress induction, mitochondria and microtubules disruption, cytochrome c release and caspases activation [1]. Other authors showed that quercetin activates the mitochondrial apoptotic pathway, since it allowed the increase of caspase-9 and BAX expression, associated with a decrease on anti-apoptotic proteins expression levels, such as BCL-2 [45]. The TNFrelated apoptosis-inducing ligand (TRAIL) is a member of the tumor necrosis factor (TNF) superfamily remarkably known for its ability inducing apoptosis selectively in several malignant cells. Curiously it was found that quercetin can promote cell death by apoptosis through TRAIL [36]. Accordingly, in 2014, Liu and colleagues demonstrated that the oral administration of $2 \mathrm{mg} / \mathrm{kg}$ of quercetin causes TRAIL-mediated inhibition of tumor growth in ovarian cancer xenografts, inducing caspase 3 activation, and therefore apoptosis [46].

In relation to apoptosis, there are also many studies that have demonstrated that quercetin has effects on BCL-2 protein family [34, 47-50]. In fact, some authors have verified that incubation with quercetin induces an increase in BAX expression with a concomitant reduction in the BCL-2 levels, indicating that quercetin induces cell death through apoptosis by the intrinsic pathway $[47,48]$. Besides that, it has been also demonstrated that apoptosis induced by quercetin could be mediated by other proteins of BCL-2 family such as BAD, MCL-1 and BCL-XL [26, 33, 49, 50].

Heat shock proteins (HSP) are highly expressed in tumor cells, being markedly related to chemotherapy drug resistance and cancer cells adaptation and survival under stress conditions. At molecular level, the formation of a complex between the HSP and mutant P53, allows tumor cells to overcome the cell cycle blockage mechanism. It was found that quercetin inhibit the production of HSP in different cancer cell lines, including leukemia, colon and breast cancer and that it can provide an anti-cancer approach also through this mechanism [35]. The action of quercetin on the heat shock proteins has been known for some years. In fact, in 1994 was published a research paper in which the aim was to investigate the possible involvement of heat shock proteins and apoptosis in the anti-cancer activity of quercetin. It was found that that quercetin inhibited the synthesis of HSP70 in several cancer cell lines. These results suggest that quercetin have an antitumor activity by inducing apoptosis and that HSP70 may affect quercetin-induced apoptosis [51]. More recently, in 2009, a study in prostate cancer cells demonstrate that quercetin promotes apoptosis by the downregulation of HSP90 levels. The authors observed that quercetin-induced HSP90 depletion results in reduced cell viability, induction of apoptosis and activation of caspases. Interestingly, these effects were not observed in normal prostate epithelial cells but only in tumor cells, demonstrating the quercetin selectivity to cancer cells [52]. Consistent with the in vitro studies discussed some authors have also demonstrated in animal models of cancer that quercetin is able to induce cell death through apoptosis [44, 46, 53].

Several authors indicate that apoptosis mediated by quercetin may induce protein stress with consequent disruption of microtubules, release of cytochrome $\mathrm{c}$ and cascade activation of caspase $[1,48]$. Thus, quercetin is characterized according to some authors as a prooxidant compound [25, 54]. However, other authors attribute to quercetin an antioxidant capacity [23, 48]. The dual action of pro- or anti-oxidant of the quercetin depends mainly on the concentration that is used. However, both characteristics emphasize the anticancer activities of the quercetin, because, if on the one hand a low concentration of quercetin confers antioxidant capacity, which is a benefit in cancer prevention, on the other hand, in a treatment situation, higher concentrations of quercetin may induce oxidative stress which triggers many types of cell death.

\section{QUERCETIN EFFECT ON MULTIDRUG RE- SISTANCE}

Recent results have demonstrated that quercetin has effects on multidrug resistance (MDR) reversion, which reinforces the promising effect of quercetin 
against cancer. It is known that multidrug resistance can impair the effectiveness of different cytostatic drugs and that it is associated with the up-regulation of efflux proteins. Some of the described efflux proteins are p-glycoprotein (PGP) and the members of multidrug resistance associated protein family (MRP's), like MRP1, both belonging to the superfamily of ABC transporters. These efflux pumps extrude chemotherapeutic agents to the outside of cells compromising its intracellular action. MRP1 (ABCC1) has a wide specificity to transport substrates, like antineoplastic and therapeutic drugs, sulphate- and glutathione-conjugates and organic anions. MRP2 (ABCC2) is strictly related to MRP1, since it also has large substrate specificity, including lipophilic substances conjugates and uncharged compounds. Related with this, a strategy to overcome MDR mediated by these extrusion proteins can be based on the inhibition of these transporters [35]. In this context, some studies found that quercetin interacts with PGP as a competitive inhibitor, blocking its activity. It was observed that this interaction with PGP is carried out at ATP binding site or substrate binding site. Quercetin can also induce a reduction of PGP $[23,24]$. Moreover, other studies have shown that there is an interaction between MRP1 and quercetin. This compound is able to reduce intracellular concentration of glutathione that is needed to efflux through MRP1, acting as a substrate, and consequently causing competitive inhibition. This mechanism of action decreases the efflux through MRP1 by binding directly or indirectly to the binding sites of ATP. In parallel, quercetin also modulates MRP1 expression [23, 24, 35].

Regarding in vivo studies, in 2004, Wang and coworkers have shown that the oral administration of 40 $\mathrm{mg} / \mathrm{kg}$ quercetin increased the maximum concentration of digoxin, a PGP substrate in pigs [55]. Latter, a 2006 study showed that the administration doses of 2.5, 7.5 and $15 \mathrm{mg} / \mathrm{kg}$ of quercetin to female Sprague-Dawley rats inhibits both MDR transporter-mediated efflux of tamoxifen and its first-pass metabolism [56]. Finally, in 2009 a study conducted in healthy humans showed that the treatment with $500 \mathrm{mg}$ of quercetin during 7 days induced an increase of fexofenadine concentrations in blood plasma, probably through PGP inhibition mediated efflux [57].

\section{QUERCETIN EFFECT ON CELL INVASION}

Some studies have also demonstrated that tumor cells respond to quercetin through the suppression of matrix metalloproteinases (MMPs) secretion that may lead to the decrease of cell invasion activity and migra- tion. More specifically, studies have shown that quercetin has the capacity to decrease MMP-2 and -9 expression that have a proeminent effect on cancer cell invasion and metastization [3, 58-64]. In this context, in 2004 Zhang and colleagues [60] had demonstrated that quercetin is capable of reducing the invasive potential of a melanoma cell line by decreasing proMMP-9 through PKC pathway [60]. In their study, Vijayababu and co-authors [61] demonstrated that the treatment of prostate cancer cells with quercetin decreased MMP-2 and MMP-9 expression in a dosedependent way [61]. Another study also demonstrated that quercetin is capable of reduce the MMP-3 activity in a dose-dependent manner in a breast carcinoma cell line [62]. In turn, in an animal model of breast cancer, it was observed that intraperitoneal injections of quercetin $(10 \mathrm{mg} / \mathrm{Kg})$ inhibited tumor growth by about $50 \%$ in comparison to control rats. In these animals it was also observed a decrease of MMP-2 expression in response to the treatment with quercetin. The quercetin treatment started $3 \mathrm{~h}$ before tumor cell inoculation. Quercetin was dissolved in $0.3 \mathrm{~mL}$ of Nujol and administered during 15 consecutive days [63]. In 2013, it was also observed that quercetin inhibited MMP-2 and MMP-9 expression and activity in oral cancer cells [64]. Another study performed in melanoma cells showed that the treatment with quercetin induces the inhibition of cell proliferation, cell death by apoptosis and a suppression in their potentials invasive and migratory. In molecular terms it was observed that quercetin interferes with STAT3 phosphorylation inhibiting STAT3 activation. In consequence, the STAT3 inhibition induced a down-regulation of STAT3 targeted genes involved in cell migration and invasion like MMP-2 and MMP-9 [65]. In summary, these results lead to the important conclusion that quercetin can influence the migration and invasiveness capacity of the tumor cells.

\section{QUERCETIN EFFECT ON NEOVASCULARI- ZATION}

Neovascularization as a consequence of angiogenesis, is an important step for the progression of metastasis. Several studies have demonstrated that quercetin is capable of inhibiting tumor angiogenesis [66-68]. In a mammary carcinoma animal model, Kong and colleagues demonstrated that quercetin can reduce the incidence and the tumor growth of a mammary carcinoma chemically induced by 7,12dimethylbenzanthracen (DMBA). Quercetin was mixed in the food at $3 \%$ of the diet weight. These results are the consequence of the inhibition, by quercetin, of the 
expression of angiogenesis-related growth factors such as VEGF and bFGF [68]. In turn, in 2012 Pratheeshkumar and colleagues showed the antiangiogenic activity of quercetin. Through in vitro and in vivo assays, the authors demonstrated that quercetin significantly inhibited neovascularization, cell invasion and migration, and endothelial cells tube formation. Quercetin also suppressed VEGF levels and VEGF receptor 2 (VEGFR-2) phosphorylation and, consequently, regulating AKT/mTOR/P70S6K signaling pathway. In prostate xenograft mouse model, the intraperitoneal treatment with quercetin $(20 \mathrm{mg} / \mathrm{kg})$ during 16 days significantly reduced tumor growth. In summary, these results suggest that quercetin inhibits tumor angiogenesis by regulating important steps of the angiogenic cascade and interfering with angiogenesis signaling pathways [66]. Latter, in 2013 Long and colleagues investigated the antitumor activity of PEGylated liposomal quercetin (Lipo-Que) on cisplatin-sensitive and cisplatin-resistant ovarian tumor xenograft models. The authors have shown that in both tumor models, LipoQue (50 mg/kg every three-day for 27 days) suppressed tumor growth through apoptosis induction and microvessel density decrease [69]. In turn, in 2014 Zhao et al. conducted a study that aimed to evaluate the effect of quercetin on angiogenesis in larval zebrafish and human umbilical vein endothelial cells. In this study, the authors found that, in transgenic zebrafish embryos quercetin induces a disruption on intersegmental vessels, dorsal aorta and posterior cardinal formation. In human umbilical vein endothelial cells quercetin inhibited cell viability, VEGFR-2 expression and tube formation in a dose-dependent manner [70].

\section{QUERCETIN AS GLUT-1 INHIBITOR}

Finally, it is known that the expression of GLUT-1 is increased in many solid tumors which, in turn, promotes their tumorigenesis. It has also been mentioned that flavonoids are potent inhibitors of the influx of glucose and has been demonstrated even that flavonols such as quercetin, inhibit the tyrosine kinase ATP binding and therefore are also able to competitively inhibit the GLUT-1. In fact, although the exact mechanism through which quercetin inhibits the GLUT-1 is not yet fully clarified, in 2001 Vera and coworkers demonstrated that quercetin interacts with the ATP-binding sites of the GLUT-1, competitively inhibiting the activity of this transporter [14]. Later, in 2011, the same research group reinforced the idea that quercetin is a competitive inhibitor of GLUT-1, through the binding to an exofacial carrier this site. Furthermore, it appears that the binding of GLUT-1 with quercetin triggers a conformational change of the carrier which, in turn, affects the glucose binding site $[11,71]$.

Thus, due to its antioxidant, anti-inflammatory, antiproliferative, anti-angiogenic and pro-apoptotic properties and also due to its ability to interact with different biochemical, immunological and, consequently, genetic factors that support the development and maintenance of tumor, quercetin can be considered as a natural compound with anti-cancer properties [26] (Fig. 4). In a 2000 paper Hanahan and Weinberg [72] have defined the six 'hallmarks of cancer'. Later, in 2011, the same authors enlarged the list of 'hallmarks of cancer' to ten [73]. Therefore, taking into account that quercetin interferes in different pathways defined as "hallmarks of cancer", like inducing angiogenesis and resisting to cell death, this compound can be defined as a multi-target inhibitor with synergistic and pleiotropic effects in cancer cells [26].

\section{COMBINATION THERAPY}

The drug combination has been used in treatment of several diseases in order to obtain synergistic effects and reduce side effects [74]. In cancer, besides the association of drugs commonly used in chemotherapy have also been investigated the combined effect of these drugs with natural compounds. So, there are already different studies in which is intended to clarify the therapeutic effect of quercetin in combination with several drugs used in the cancer treatment like doxorubicin [75, 76], 5-fluorouracil [77-79], cisplatin [80-83], dacarbazin [84], etoposide [77], daunorubicin [85], temozolomide [85], camptothecin [77], gemcitabine [55, 86], lapatinib [87], oxaliplatin [83], sorafenib [88], tamoxifen [89] and trichostatin A [90] (Table 1).

Emphasizing the potential that this kind of combined therapies has in the treatment of oncological diseases, studies of combination therapy with quercetin have been carried out in several types of cancers such as prostate cancer [77], colorectal cancer [78], hepatocellular carcinoma (HCC) $[75,81]$, lung cancer [82, 90], pancreatic carcinoma [53, 85] and breast cancer [74, 87, 89] (Table 1).

Regarding to the mechanisms of action of the combined therapy with quercetin, there are several biochemical pathways involved. The interference with P53 expression and its associated mechanisms is one of the most studied approaches. Therefore, recent studies have shown that there is a link between P53 expression and the response to quercetin of tumor cells and animal cancer models. In 2012, Wang and colleagues studied the effect of quercetin on the antitumor effects of 
Table 1. Combined treatments of quercetin with chemotherapeutic drugs. Studies are ordered according to the observed mechanism of action.

\begin{tabular}{|c|c|c|c|c|c|}
\hline Type of Study & Chemotherapy Drug & Cancer Type & Mechanism of Action & Results & Reference \\
\hline $\begin{array}{l}\text { In vitro and in } \\
\text { vivo }\end{array}$ & Doxorubicin & $\begin{array}{l}\text { Hepatocellular carci- } \\
\text { noma }\end{array}$ & $\begin{array}{l}\text { Down-regulation of } \\
\text { BCL-2 expression }\end{array}$ & $\begin{array}{l}\text { Potentiation of quercetin } \\
\text { effect }\end{array}$ & {$[75]$} \\
\hline $\begin{array}{l}\text { In vitro and in } \\
\text { vivo }\end{array}$ & Trichostatin A & Lung cancer & $\begin{array}{l}\text { Regulation of P53 ex- } \\
\text { pression }\end{array}$ & $\begin{array}{c}\text { Trichostatin A anticancer } \\
\text { effect }\end{array}$ & {$[90]$} \\
\hline In vitro & $\begin{array}{l}\text { 5-fluorouracil, etoposide } \\
\text { and camptothecin }\end{array}$ & $\begin{array}{l}\text { Colorectal and prostate } \\
\text { cancer }\end{array}$ & $\begin{array}{l}\text { Treatment of P53 wt - } \\
\text { cells with quercetin } \\
\text { reduced drug-induced up- } \\
\text { regulation of P53, P21 } \\
\text { and BAX }\end{array}$ & $\begin{array}{c}\text { Combination effect is influ- } \\
\text { enced by quercetin concen- } \\
\text { tration and P53 status of the } \\
\text { cells }\end{array}$ & {$[77]$} \\
\hline In vitro & 5-fluorouracil & Colorectal cancer & $\begin{array}{c}\text { Increase of P53 expres- } \\
\text { sion }\end{array}$ & $\begin{array}{l}\text { Enhancement of 5- } \\
\text { fluorouracil efficiency }\end{array}$ & {$[78]$} \\
\hline In vitro & Temozolomide & Melanoma & $\begin{array}{l}\text { Modulation of P53 fam- } \\
\text { ily members such as P73 }\end{array}$ & $\begin{array}{l}\text { Sensitization of melanoma } \\
\text { cells to temozolomide }\end{array}$ & {$[84]$} \\
\hline In vitro & Cisplatin & $\begin{array}{l}\text { Non-small cell lung } \\
\text { carcinoma }\end{array}$ & $\begin{array}{l}\text { Down-regulation of anti- } \\
\text { apoptotic proteins BCL-2 } \\
\text { and BCL-XL, and up- } \\
\text { regulation of pro- } \\
\text { apoptotic protein BAX }\end{array}$ & $\begin{array}{l}\text { Cells sensitization to apop- } \\
\text { tosis }\end{array}$ & {$[82]$} \\
\hline In vitro & Cisplatin & $\begin{array}{l}\text { Hepatocellular carci- } \\
\text { noma }\end{array}$ & $\begin{array}{l}\text { Combined therapy inter- } \\
\text { fered with apoptosis and } \\
\text { cell cycle progression by } \\
\text { modulating the expres- } \\
\text { sion of numerous genes, } \\
\text { like P16 and P21 }\end{array}$ & $\begin{array}{l}\text { Combination therapy } \\
\text { yielded synergistic effects }\end{array}$ & [81] \\
\hline In vitro & Tamoxifen & Breast cancer & $\begin{array}{l}\text { Decrease on BCL-2 } \\
\text { protein expression }\end{array}$ & $\begin{array}{l}\text { Apoptosis increase in the } \\
\text { combined treatment }\end{array}$ & [89] \\
\hline In vitro & Daunorubicin & Pancreatic cancer & $\begin{array}{l}\text { Decrease in PGP gene } \\
\text { expression }\end{array}$ & $\begin{array}{l}\text { Sensitization to daunorubi- } \\
\text { cin by PGP modulation }\end{array}$ & {$[85]$} \\
\hline In vitro & Adriamycin & Breast cancer & $\begin{array}{l}\text { Inhibition of the PGP } \\
\text { function }\end{array}$ & $\begin{array}{l}\text { Potentiation of adriamycin } \\
\text { growth-inhibitory activity }\end{array}$ & {$[93]$} \\
\hline In vitro & Cisplatin and oxaliplatin & Ovarian cancer & $\begin{array}{l}\mathrm{NF}-\kappa \mathrm{B} \text { expression inhibi- } \\
\text { tion }\end{array}$ & $\begin{array}{l}\text { Cells sensitization to cis- } \\
\text { platin and oxaliplatin }\end{array}$ & {$[83]$} \\
\hline In vitro & 5-fluorouracil & Esophageal cancer & $\begin{array}{l}\mathrm{pI \kappa B} \alpha \text { increased expres- } \\
\text { sion }\end{array}$ & $\begin{array}{l}\text { Cells sensitization to } 5 \text { - } \\
\text { fluorouracil }\end{array}$ & {$[79]$} \\
\hline In vitro & $\begin{array}{l}\text { Topotecan and gemcit- } \\
\text { abine }\end{array}$ & Fibrossarcoma & Reducing HSP70 levels & $\begin{array}{l}\text { Cells sensitization to the } \\
\text { topotecan and gemcitabine } \\
\text { cytotoxic activity }\end{array}$ & {$[86]$} \\
\hline In vitro & Temozolomide & Glioblastoma & HSP27 inhibition & $\begin{array}{l}\text { Sensitization of glioblas- } \\
\text { toma cell lines to temo- } \\
\text { zolomide }\end{array}$ & [94] \\
\hline In vitro & Sorafenib & Glioma & $\begin{array}{l}\text { Heat shock proteins } \\
\text { blocking }\end{array}$ & $\begin{array}{l}\text { Potentiation of sorafenib } \\
\text { pro-apoptotic properties }\end{array}$ & {$[88]$} \\
\hline $\begin{array}{l}\text { In vitro and in } \\
\text { vivo }\end{array}$ & Doxorubicin & Breast cancer & $\begin{array}{l}\text { Quercetin suppressed } \\
\text { intratumoral HIF-1 } \alpha\end{array}$ & $\begin{array}{l}\text { Enhancement of doxorubi- } \\
\text { cin therapeutic efficacy and } \\
\text { doxorubicin side effects } \\
\text { reduction }\end{array}$ & {$[76]$} \\
\hline
\end{tabular}


doxorubicin on HCC cell lines, on normal liver cells and in a HCC animal model. The authors demonstrated that quercetin selectively sensitized doxorubicin induced cytotoxicity against HCC cells while protecting normal liver cells. This effect is P53-dependent and involved down-regulation of BCL-2 expression. In this study it was also observed that the combined treatment of doxorubicin $(4 \mathrm{mg} / \mathrm{kg}$, intraperitoneally, once a week) with quercetin (100 mg / $\mathrm{kg}$, intraperitoneally, 3 times per week) induced a decrease in the growth of HCC xenografts in nude mice [75]. Something similar was observed by Chan et al. [90], which through the use of cells and animal models of lung cancer, they verified that quercetin potentiates the effect of trichostatin A in a P53-dependent manner [90]. Also in 2012 Temesgen and colleagues [77] studied the dualmode interaction of quercetin and several DNAdamaging drugs in colorectal and prostate cancer cells, namely 5-fluorouracil, etoposide and camptothecin. In this study, quercetin revealed to synergize or counteract with the chemotherapeutic drugs and that the combination effect is dependent on the P53 status of the cancer cells [77]. Similarly, the results obtained by Xavier et al. suggests the potential applicability of quercetin for enhancement of 5-fluorouracil efficiency in the therapy of colorectal cancer with microsatellite instability, especially in P53 wild-type tumors [78]. In turn, Thangasamy et al. [84] have demonstrated that quercetin can sensitize melanoma cells to temozolomide and that the mechanisms of sensitization involve modulation of P53 family members such as P73 [84]. Correlating with its action on the P53, some studies have demonstrated the quercetin is capable to chemosensitize tumor cells through changes in the cell cycle and intervention in several signaling pathways related to apoptosis. In 2006 Kuhar and colleagues [85] demonstrated that quercetin has increased the cisplatin-induced apoptosis to $30.2 \%$ in non-small cell lung carcinoma cells. Thus, quercetin follow down-regulated the anti-apoptotic proteins, BCL-2 and BCL-XL, and up-regulated the proapoptotic protein BAX. Also the cytochrome $\mathrm{c}$ and the apoptosis-inducing factor were implicated in the apoptotic process. Thus, quercetin might act as an effective chemosensitizer in non-small cell lung carcinoma by regulating the expression of different apoptosis-related genes [82]. Concerning HCC, in a study [81] performed in cell lines it was found that the combination of quercetin with cisplatin was effective in inducing growth suppression and apoptosis, when compared with treatment with quercetin or cisplatin alone. It was observed that quercetin has suppressive activity against HCC tumor cells used through P16-mediated cell cycle arrest and apoptosis and quercetin combination with cisplatin yielded synergistic inhibitory effects suppressing cell growth and inducing apoptosis [81].

In 2014, in a study by Kavithaa and colleagues [89], the combined efficacy of quercetin with tamoxifen in a breast cancer cell line was evaluated. This study showed greater reduction in the cell viability resulting of incubation of quercetin combined with tamoxifen when compared with cells incubated with tamoxifen and quercetin as monotherapy. An increase in apoptosis accompanied by a decreasing on BCL-2 protein expression was found in the combined treatment when compared to each compound individually considered [89].

As referred previous, multidrug resistance constitutes a barrier for the success of chemotherapy There are several mechanisms that can make a neoplastic cell resistant to chemotherapeutic agents like the expression of transmembrane proteins such as the efflux $\mathrm{ABC}$ proteins or vault proteins [91, 92]. The use of combination therapies have been developed in recent decades also in order to reverse the intrinsic resistance that certain tumor cells express to some drugs. Several studies showed that quercetin may intensify action of cytostatic drugs and suppress the multidrug resistance phenomenon [85, 93]. As early as 1994 a study had shown that quercetin basis for the potential therapeutic use of quercetin in combination with adriamycin as an anticancer approach against multidrug-resistant breast cancer cells [93]. In turn, Borska and colleagues [85] have demonstrated that in pancreatic cancer cells, quercetin affects the expression and PGP function, an ABC efflux pump, in a concentration dependent manner. Moreover, quercetin leads to a decrease greatly potentiates the growth-inhibitory activity of adriamycin on MCF-7 human breast adriamycin resistant cancer cells. The results indicate that quercetin inhibit the PGP efflux pump-activity in a dose-dependent manner. In conclusion, these results provide the biological in PGP gene expression. Thus, quercetin may be considered as a potential modulator of PGP, increasing the sensitivity of tumor cells to chemotherapeutic agents such as daunorubicin [85].

Some studies have shown that the nuclear factor- $\mathrm{kB}$ (NF-kB) plays a central role in the development of multidrug resistance. So, the inhibition of $N F-\kappa B$ could improve the cytotoxic effect of anti-cancer drugs $[79,83]$. Besides these facts, it is also known that quercetin exerts antitumour activity by inhibiting the activation of NF-кB. Therefore, in 2011 Nessa [83] and collaborators suggest that prior incubation of ovarian can- 
cer cells with quercetin helps to reduce the expression of NF- $\mathrm{kB}$ and hence lower the resistance to cisplatin and oxaliplatin [83]. Latter, in 2013, Chuang-Xin and colleagues [79] have demonstrated that quercetin acts synergistically with 5 -fluorouracil significantly inhibiting esophageal cancer cells growth and stimulating apoptosis. This effect was related with the expression of $\mathrm{pI \kappa \textrm {B }} \alpha$ (a phosphorylated inhibitory molecule of $N F-\kappa B$ ), that was increased after exposure to 5 -fluorouracil alone but decreased after exposure to quercetin or the combination of both [79].

Heat shock proteins have also been correlated with the intrinsic resistance that some tumor cells exhibit to chemotherapy [86, 88]. In 1996 Sliutz et al. [86] investigated whether HSP70 overexpression altered the therapeutic efficacy of topotecan and gemcitabine in HSP70-overexpressing cells and control cells. The authors have found that quercetin was effective in reducing HSP70 levels. Quercetin also sensitized cells to the cytotoxic activity of topotecan and gemcitabine. These data suggest that quercetin may be used as a sensitizer to chemotherapeutic drugs [86]. In a similar way, human glioblastoma cells proved to be insensitive to temozolomide alone, since this drug significantly increased HSP27 phosphorylation. However, quercetin or siRNA against HSP27 combined with temozolomide decreased HSP27 phosphorylation and significantly inhibited its expression, leading to glioblastoma cell growth inhibition [94].

Some anti-neoplastic drugs like doxorubicin and oxaliplatin are efficient in cancer therapy, but also induce severe secondary effects such as hepatotoxicity, cardiotoxicity and neuropathy [95-97]. These secondary effects are frequently associated with the generation of reactive oxygen species that are cytotoxic to normal cells. Some studies have demonstrated that the antioxidant and anti-inflammatory properties of quercetin make it a promising compound to be combined with anticancer agents, in order to attenuate their secondary effects. These data further reinforce the therapeutic potential of combination therapies with quercetin for the treatment of oncological diseases [95-97]. Azevedo and colleagues have demonstrated that oxaliplatin induced painful peripheral neuropathy in mice. To evaluate the effect of rutin and quercetin on neuropathy, male Swiss mice (25-35 g) received an intraperitoneal injection of saline $(10 \mathrm{~mL} / \mathrm{kg})$, rutin $(25,50$, and $100 \mathrm{mg} / \mathrm{kg}$ ) or quercetin $(25,50$, and $100 \mathrm{mg} / \mathrm{kg})$ $30 \mathrm{~min}$ before every oxaliplatin injection $(1 \mathrm{mg} / \mathrm{kg})$. In this study the authors demonstrated that in this animal model, neuropathy was prevented by rutin and quer- cetin [95]. Also in 2013, an in vitro study showed that quercetin decreased doxorubicin-induced cytotoxicity and protected the cardiomyocytes from doxorubicininduced heart damage. Quercetin significantly supported cell survival, since it prevented normal cell apoptosis and allowed the rearrangement of cytoskeleton [96]. In 2014, Dong and colleagues demonstrated the clinical potential of quercetin in preventing doxorubicin-induced cardiomyopathy. In this study, quercetin induces a decrease in BID, P53 and oxidase (Nox1 and P47) expression and an increase of BCL-2 and BMI-1 expression in cardiomyocytes, giving protection against doxorubicin toxicity [97].

In a similar manner to that shown by chemotherapy, some studies have evaluated the combined effect of quercetin and radiotherapy [98-102]. In 1997 a study which investigated the combined effect of quercetin with X-rays on Reuber H35 hepatoma cells was carried out [102]. It was observed that quercetin enhance the effect of radiation on cell death, by decreasing radiation-induced DNA damage repair and reducing cell repopulation [102]. Varadkar [100] and co-authors have studied the combined effect of quercetin and radiation on the PKC activity. It is known that PKC is one of the majors contributors for the radioresistance following radiotherapy. In this case, the authors observed that irradiation alone increased PKC activity [100]. On the other hand, quercetin inhibited PKC activity induced by radiation. Thus, the suppression of PKC activity by quercetin can be an approach to prevent the development of radioresistance [100]. Besides that, also Lin and colleagues [101] demonstrated, in vitro and in vivo, that quercetin increases tumor radiosensitivity. In addition to the quercetin sensitize a wide variety of cell lines for radiation therapy, it was also showed the radiosensitization effect of quercetin in a human colorectal cancer xenograft model. At a cellular level, it was observed that quercetin inhibits ATM kinase, that is normally activated in response to DNA damage. In vivo, it was observed that the mean doubling time of tumor xenografts was significantly increased in irradiated mice treated with quercetin, intraperitoneally, $1 \mathrm{~h}$ before radiation [101]. Simultaneously, there are also some studies which show that quercetin has the ability of protecting healthy tissue from the effects of radiation, minimizing the side effects of radiotherapy [103-105].

The cancer treatment with chemotherapy and radiotherapy has two major problems, the unspecific toxicity towards to normal tissues and the development of tumor resistance to therapies. Thereby, in the last few 
years efforts have been made to find strategies to overcome these obstacles. It has been shown in several studies that quercetin has the ability to sensitize tumor cells to chemotherapy and radiotherapy preserving adjacent normal tissues. These results reinforce the assumption that quercetin can be considered as an anticancer agent.

\section{CONCLUSION}

Flavonoids are polyphenolic compounds present in plant-derived foods that exhibit several biological effects on human health. These compounds have the ability to reduce the risk of chronic diseases, like cardiovascular diseases and cancer. Quercetin is a bioactive flavonoid, belonging to flavonol class, present in fruits and vegetables and shows anti-oxidants, antiinflammatory and anti-angiogenic effects, being proposed as a potential anticancer agent. In fact, in molecular terms, it has been demonstrated that quercetin interferes with different proteins such as PKC, cdc25 phosphatase, PI3K, protein kinase B phosphorylated (P-Akt), DNA topoisomerase II and N-terminal kinase c-Jun (JNK) that are implicated in cell proliferation and signal transduction pathways. Quercetin has also the capacity to inhibit the mutated P53. Regarding the effect on cell cycle, it is known that in different types of tumor cells the treatment with quercetin causes stops in cell cycle at $\mathrm{G} 2 / \mathrm{M}$ phase or $\mathrm{G} 1$ phase. In relation to apoptosis, there are also many studies that have demonstrated that quercetin has effects on BCL-2 protein family, like BAX, BCL-2, BAD, MCL-1 and BCL-XL. It has also been found that quercetin inhibits heat shock proteins production in different tumor cell lines providing an anti-cancer approach through this mechanism. Recently, has emerged results which demonstrated that quercetin has effects on MDR reversion, more specifically, some studies found that quercetin interacts with PGP and MRP1 as a competitive inhibitor which reinforces the promising effect of quercetin against cancer. Some studies have also demonstrated that tumor cells respond to quercetin through the suppression of matrix metalloproteinases (MMPs) secretion that may lead to the decrease of cell invasion activity and migration. Quercetin has also a dual action as a pro- or antioxidant compound and both characteristics emphasize its anti-cancer properties. Neovascularization, which involves angiogenesis, is an important step for the progression of metastasis. Several studies have demonstrated that quercetin is capable of inhibiting tumor angiogenesis, which confers to this compound the capacity to interfere in cancer progression and metastization. Quercetin is also a potent inhibitor of glucose influx which is due, in part, to its interaction with the ATPbinding sites of the GLUT-1 competitively inhibiting the activity of this transporter. It has been shown that quercetin has the ability to sensitize tumor cells to chemotherapy and radiotherapy preserving adjacent normal tissues. Quercetin can act on the chemosensitization but also as chemoprotective, protecting normal cells of the side effects that results from chemotherapy, which obviously provides notable advantages in their use in anticancer treatment. These results reinforce the assumption that quercetin can be considered as an anticancer agent. In summary, due to its biological properties, namely pro-/anti-oxidant, anti-inflammatory, antiangiogenic, anti-proliferative and pro-apoptotic, and also due to its ability to interact with different biochemical, genetic and immunological factors that support the development and maintenance of the tumor, quercetin can be regarded as a natural compound with anti-cancer abilities. Despite the wide variety of studies already conducted, the quercetin's action mechanisms as a monotherapy or in combination therapy still need further investigation, particularly with regard to in vivo studies and later clinical trials.

\section{CONFLICT OF INTEREST}

The authors confirm that this article content has no conflict of interest.

\section{ACKNOWLEDGEMENTS}

Ana Filipa Brito and Ana Salomé Pires would like to thank the Portuguese Foundation for Science and Technology for the award of PhD scholarships (SFRH / BD / 61378 / 2009 and SFRH / BD / 75300 / 2010).

The authors thank to the FTC, Portugal (Strategic Project PEst-C/SAU/UI3282/2013 and UID/NEU/ 04539/2013), COMPETE-FEDER.

\section{REFERENCES}

[1] Nomura, M.; Takahashi, T.; Nagata, N.; Tsutsumi, K.; Kobayashi, S.; Akiba, T.; Yokogawa, K.; Moritani, S.; Miyamoto, K. Inhibitory mechanisms of flavonoids on insulinstimulated glucose uptake in MC3T3-G2/PA6 adipose cells. Biol. Pharm. Bull., 2008, 31, 1403-1409.

[2] Park, J. B. Flavonoids are potential inhibitors of glucose uptake in U937 cells. Biochem. Biophys. Res. Commun., 1999, 260, 568-574.

[3] Kanadaswami, C.; Lee, L.; Lee, P. H.; Hwang, J. J.; Ke, F. C.; Huang, Y. T.; Lee, M. T. The antitumor activities of flavonoids. In Vivo (Brooklyn), 2005, 19, 895-910.

[4] Seufi, A. M.; Ibrahim, S. S.; Elmaghraby, T. K.; Hafez, E. E. Preventive effect of the flavonoid, quercetin, on hepatic cancer in rats via oxidant/antioxidant activity: molecular and histological evidences. J. Exp. Clin. Cancer Res., 2009, $28,80-88$. 
[5] Adebamowo, C. A.; Cho, E.; Sampson, L.; Katan, M. B.; Spiegelman, D.; Willett, W. C.; Holmes, M. D. Dietary flavonols and flavonol-rich foods intake and the risk of breast cancer. Int. J. Cancer, 2005, 114, 628-633.

[6] Tapas, A. R.; Sakarkar, D. M.; Kakde, R. B. Flavonoids as nutraceuticals: a review. Trop. J. Pharm. Res., 2008, 7, 1089-1099.

[7] Kite, G. C.; Porter, E. A.; Denison, F. C.; Grayer, R. J.; Veitch, N. C.; Butler, I.; Simmonds, M. S. J. Data-directed scan sequence for the general assignment of $\mathrm{C}$ glycosylflavone $\mathrm{O}$-glycosides in plant extracts by liquid chromatography-ion trap mass spectrometry. J. Chromatogr. A, 2006, 1104, 123-131.

[8] Kite, G. C.; Veitch, N. C. Identification of common glycosyl groups of flavonoid O-glycosides by serial mass spectrometry of sodiated species. Rapid Commun. Mass Spectrom., 2011, 25, 2579-2590.

[9] Martin, H-J.; Kornmann, F.; Fuhrmann, G. F. The inhibitory effects of flavonoids and antiestrogens on the Glut1 glucose transporter in human erythrocytes. Chem. Biol. Interact., 2003, 146, 225-235.

[10] Strobel, P.; Allard, C.; Perez-Acle, T.; Calderon, R.; Aldunate, R.; Leighton F. Myricetin, quercetin and catechingallate inhibit glucose uptake in isolated rat adipocytes. Biochem. J., 2005, 386, 471-478.

[11] Amann, T.; Hellerbrand, C. GLUT1 as a therapeutic target in hepatocellular carcinoma. Expert. Opin. Ther. Targets, 2009, 13, 1411-1427.

[12] Pérez, A.; Ojeda, P.; Ojeda, L.; Salas, M.; Rivas, C. I.; Vera, J. C.; Reyes, A. M. Hexose transporter GLUT1 harbors several distinct regulatory binding sites for flavones and tyrphostins. Biochemistry, 2011, 50, 8834-8845.

[13] Vargas, A. J.; Sittadjody, S.; Thangasamy, T.; Mendonza, E. E.; Limesand, K. H.; Burd, R. Exploiting tyrosinase expression and activity in melanocytic tumors: quercetin and the central role of p53. Integr. Cancer Ther., 2011, 10, 328340.

[14] Vera, J. C.; Reyes, A. M.; Velásquez, F. V.; Rivas, C. I.; Zhang, R. H.; Strobel, P.; Slebe, J. C.; Nuñez-Alarcón, J.; Golde, D. W. Direct inhibition of the hexose transporter GLUT1 by tyrosine kinase inhibitors. Biochemistry, 2001, 40, 777-790.

[15] Gilbert, E. R.; Liu, D. Anti-diabetic functions of soy isoflavone genistein: mechanisms underlying its effects on pancreatic $\beta$-cell function. Food. Funct., 2013, 4, 200-212.

[16] Crespy, V.; Williamson, G. A review of the health effects of green tea catechins in in vivo animal models. J. Nutr., 2004, 134, 3431S-3440.

[17] Williamson, G. Possible effects of dietary polyphenols on sugar absorption and digestion. Mol. Nutr. Food Res., 2013, 57, 48-57.

[18] Wein, S.; Schrader, E.; Rimbach, G.; Wolffram, S. Oral green tea catechins transiently lower plasma glucose concentrations in female db/db mice. J. Med. Food, 2013, 16, 312-317.

[19] Pereira, D. F.; Cazarolli, L. H.; Lavado, C.; Mengatto, V.; Figueiredo, M. S. R. B.; Guedes, A.; Pizzolatti, M. G.; Silva, F. R. M. B. Effects of flavonoids on $\alpha$-glucosidase activity: potential targets for glucose homeostasis. Nutrition, 2011, 27, 1161-1167.

[20] Babu, P. V. A.; Liu, D.; Gilbert, E. R. Recent advances in understanding the anti-diabetic actions of dietary flavonoids. J. Nutr. Biochem., 2013, 24, 1777-1789.

[21] Mohan, S.; Nandhakumar, L. Role of various flavonoids: Hypotheses on novel approach to treat diabetes. J. Med. Hypotheses Ideas, 2014, 8, 1-6.
[22] Kim, J. H.; Kang, M. J.; Choi, H. N.; Jeong, S. M.; Kim, J. I. Quercetin attenuates fasting and postprandial hyperglycemia in animal models of diabetes mellitus. Nutr. Res. Pract., 2011, 5, 107-111.

[23] Chen, C.; Zhou, J.; Ji, C. Quercetin: a potential drug to reverse multidrug resistance. Life Sci., 2010, 87, 333-338.

[24] Akiyama, T.; Ishida, J.; Nakagawa, S.; Ogawara, H.; Watanabe, S.; Itoh, N.; Shibuya, M.; Fukami, Y. Genistein, a specific inhibitor of tyrosine-specific protein kinases. $J$. Biol. Chem., 1987, 262, 5592-5595.

[25] Ferraresi, R.; Troiano, L.; Roat, E.; Lugli, E.; Nemes, E.; Nasi, M.; Pinti, M.; Fernandez, M. I. G.; Cooper, E. L.; Cossarizza, A. Essential requirement of reduced glutathione (GSH) for the anti-oxidant effect of the flavonoid quercetin. Free Radic. Res., 2005, 39, 1249-1258.

[26] Russo, M.; Spagnuolo, C.; Tedesco, I.; Bilotto, S.; Russo, G. L. The flavonoid quercetin in disease prevention and therapy: facts and fancies. Biochem. Pharmacol., 2012, 83, 6-15.

[27] Materska, M. Quercetin and its derivatives: chemical structure and bioactivity - a review. Polish J. Food Nutr. Sci., 2008, 58, 407-413.

[28] Moon, Y. J.; Wang, L.; Dicenzo, R.; Morris, M. E. Quercetin pharmacokinetics in humans. Biopharm. Drug Dispos., 2008, 217, 205-217.

[29] Graefe, E. U.; Wittig, J.; Mueller, S.; Riethling, A. K.; Drewelow, B.; Pforte, H.; Jacobasch, G.; Derendorf, H.; Veit, M. Pharmacokinetics and bioavailability of quercetin glycosides in humans. J. Clin. Pharmacol., 2001, 41, 492499.

[30] Liu, L.; Tang, Y.; Gao, C.; Li, Y.; Chen, S.; Xiong, T.; Li, J.; Du, M.; Gong, Z.; Chen, H.; Liu, L.; Yao, P. Characterization and biodistribution in vivo of quercetin-loaded cationic nanostructured lipid carriers. Colloids Surf. B Biointerfaces, 2014, 115, 125-131.

[31] Elmore, S. Apoptosis: A review of programmed cell death. Toxicol. Pathol., 2007, 35, 495-516.

[32] Jeong, J. H.; An, J. Y.; Kwon, Y. T.; Rhee, J. G.; Lee, Y. J. Effects of low dose quercetin: Cancer cell-specific inhition of cell cycle progression. Mol. Biol., 2009, 50, 1820-1827.

[33] Priyadarsini, R. V.; Murugan, R. S.; Maitreyi, S.; Ramalingam, K.; Karunagaran, D.; Nagini, S. The flavonoid quercetin induces cell cycle arrest and mitochondriamediated apoptosis in human cervical cancer (HeLa) cells

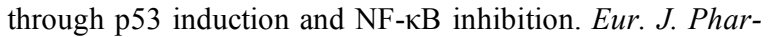
macol., 2010, 649, 84-91.

[34] van Zanden, J. J.; van der Woude, H.; Vaessen, J.; Usta, M.; Wortelboer, H. M.; Cnubben, N. H. P.; Rietjens, I. M. C. M. The effect of quercetin phase II metabolism on its MRP1 and MRP2 inhibiting potential. Biochem. Pharmacol., 2007, 74, 345-351.

[35] Lamson, D. W.; Brignall, M. S. Antioxidants and cancer III: quercetin antioxidants \& cancer: quercetin. Altern. Med. Rev., 2000, 5, 196-208.

[36] Kim, Y.; Lee, D.; Jeong, J.; Guo, Z.; Lee, Y. Quercetin augments TRAIL-induced apoptotic death: involvement of the ERK signal transduction pathway. Biochem. Pharmacol., 2009, 75, 1946-1958.

[37] Nöthlings, U.; Murphy, S. P.; Wilkens, L. R.; Henderson, B. E.; Kolonel, L. N. Flavonols and pancreatic cancer risk: the multiethnic cohort study. Am. J. Epidemiol., 2007, 166, 924-931.

[38] Lee, L-T.; Huang, Y-T.; Hwang, J-J.; Lee, A. Y-L.; Ke, FC.; Huang, C-J.; Kandaswami, C.; Lee, P-P. H.; Lee, M-T. Transinactivation of the epidermal growth factor receptor tyrosine kinase and focal adhesion kinase phosphorylation by dietary flavonoids: effect on invasive potential of human 
carcinoma cells. Biochem. Pharmacol., 2004, 67, 21032114.

[39] Williams, R. J.; Spencer, J. P. E.; Rice-Evans, C. Flavonoids: antioxidants or signaling molecules? Free Radic. Biol. Med., 2004, 36, 838-849.

[40] al-Obeidi, F. A.; Wu, J. J.; Lam, K. S. Protein tyrosine kinases: structure, substrate specificity, and drug discovery. Biopolymers, 1998, 47, 197-223.

[41] Huang, Y.; Lee, L.; Lee, P. P. H.; Lin, Y. S.; Lee, M. T. Targeting of focal adhesion kinase by flavonoids and smallinterfering RNAs reduces tumor cell migration ability. Anticancer Res., 2005, 2026, 2017-2025.

[42] Huang, Y. T.; Hwang, J. J.; Lee, P. P.; Ke, F. C.; Huang, J. H.; Huang, C. J.; Kandaswami, C.; Middleton, E.; Lee, M. T. Effects of luteolin and quercetin, inhibitors of tyrosine kinase, on cell growth and metastasis-associated properties in A431 cells overexpressing epidermal growth factor receptor. Br. J. Pharmacol., 1999, 128, 999-1010.

[43] Firdous, A. B.; Sharmila, G.; Balakrishnan, S.; Singh, P. R.; Suganya, S.; Srinivasan, N.; Arunakaran, J. Quercetin, a natural dietary flavonoid, acts as a chemopreventive agent against prostate cancer in an in vivo model by inhibiting the EGFR signaling pathway. Food Funct., 2014, 5, 2632-2645.

[44] Maso, V.; Calgarotto, A. K.; Franchi, G. C.; Nowill, A. E.; Filho, P. L.; Vassallo, J.; Saad, S. T. O. Multitarget effects of quercetin in leukemia. Cancer Prev. Res. (Phila), 2014, 7, 1240-1250.

[45] Volate, S. R.; Davenport, D. M.; Muga, S. J.; Wargovich, M. J. Modulation of aberrant crypt foci and apoptosis by dietary herbal supplements (quercetin, curcumin, silymarin, ginseng and rutin). Carcinogenesis, 2005, 26, 1450-1456.

[46] Yi, L.; Zongyuan, Y.; Cheng, G.; Lingyun, Z.; Guilian, Y.; Wei, G. Quercetin enhances apoptotic effect of tumor necrosis factor-related apoptosis-inducing ligand (TRAIL) in ovarian cancer cells through reactive oxygen species (ROS) mediated CCAAT enhancer-binding protein homologous protein (CHOP)-death receptor 5 pathway. Cancer Sci., 2014, 105, 520-527.

[47] Gao, X.; Wang, B.; Wei, X.; Men, K.; Zheng, F.; Zhou, Y.; Zheng, Y.; Gou, M.; Huang, M.; Gui, G.; Huang, N.; Qian, Z.; Wei, Y. Anticancer effect and mechanism of polymer micelle-encapsulated quercetin on ovarian cancer. Nanoscale, 2012, 4, 7021-7030.

[48] Zhang, J.; Yi, T.; Liu, J.; Zhao, Z. Z.; Chen, H. B. Quercetin induces apoptosis via the mitochondrial pathway in KB and KBv200 cells. J. Agric. Food. Chem., 2013, 61, 2188-2195.

[49] Lee, D-H.; Szczepanski, M.; Lee, Y. J. Role of BAX in quercetin-induced apoptosis in human prostate cancer cells. Biochem. Pharmacol., 2012, 75, 2345-2355.

[50] Russo, M.; Spagnuolo, C.; Volpe, S.; Tedesco, I.; Bilotto, S.; Russo, G. L. ABT-737 resistance in B-cells isolated from chronic lymphocytic leukemia patients and leukemia cell lines is overcome by the pleiotropic kinase inhibitor quercetin through Mcl-1 down-regulation. Biochem. Pharmacol., 2013, 85, 927-936.

[51] Wei, Y. Q.; Zhao, X.; Kariya, Y.; Teshihawara, K.; Ushida, A. Induction of apoptosis by quercetin: involvement of heat shock protein. Cancer Res., 1994, 54, 4952-4957.

[52] Aalinkeel, R.; Bindukumar, B.; Reynolds, J. L.; Sykes, D. E.; Mahajan, S. D.; Chadha, K. C.; Schwartz, S. A. The dietary bioflavonoid, quercetin, selectively induces apoptosis of prostate cancer cells by down-regulating the expression of heat shock protein 90. Prostate, 2008, 68, 1773-1789.

[53] Angst, E.; Park, J. L.; Moro, A.; Lu, Q. Y.; Lu, X.; Li, G.; King, J.; Chen, M.; Reber, H. A.; Go, V. L.; Eibl, G.; Hines,
O.J. The flavonoid quercetin inhibits pancreatic cancer growth in vitro and in vivo. Pancreas, 2014, 42, 223-229.

[54] Bishayee, K.; Ghosh, S.; Mukherjee, A.; Sadhukhan, R.; Mondal, J.; Khuda-Bukhsh, A.R .Quercetin induces cytochrome-c release and ROS accumulation to promote apoptosis and arrest the cell cycle in G2 / M , in cervical carcinoma : signal cascade and drug-DNA interaction. Cell. Prolif., 2013, 46, 153-163.

[55] Wang, Y. H.; Chao, P. D.; Hsiu, S. L.; Wen, K. C.; Hou, Y. C. Lethal quercetin-digoxin interaction in pigs. Life Sci., 2004, 74, 1191-1197.

[56] Shin, S-C.; Choi, J-S.; Li, X. Enhanced bioavailability of tamoxifen after oral administration of tamoxifen with quercetin in rats. Int. J. Pharm., 2006, 313,144-149.

[57] Kim, K-A.; Park, P-W.; Park, J-Y. Short-term effect of quercetin on the pharmacokinetics of fexofenadine, a substrate of P-glycoprotein, in healthy volunteers. Eur. J. Clin. Pharmacol., 2009, 65, 609-614.

[58] Lin, Y.; Tsai, P.; Lee, M. Impact of flavonoids on matrix metalloproteinase secretion and invadopodia formation in highly invasive A431-III cancer cells materials and methods materials preparation of cell lysates transfection of small interference RNA. PLoS One, 2013, 21, 1-12.

[59] Lee, D. E.; Chung, M. Y.; Lim, T. G.; Huh, W. B.; Lee, H. J.; Lee, K. W. Quercetin suppresses intracellular ROS formation, MMP activation, and cell motility in human fibrosarcoma cells. J. Food Sci., 2013, 78, H1464-1469.

[60] Zhang, X-M.; Huang, S-P.; Xu, Q. Quercetin inhibits the invasion of murine melanoma B16-BL6 cells by decreasing pro-MMP-9 via the PKC pathway. Cancer Chemother. Pharmacol., 2004, 53, 82-88.

[61] Vijayababu, M. R.; Arunkumar, A.; Kanagaraj, P.; Venkataraman, P.; Krishnamoorthy, G.; Arunakaran, J. Quercetin downregulates matrix metalloproteinases 2 and 9 proteins expression in prostate cancer cells (PC-3). Mol. Cell. Biochem., 2006, 287, 109-116.

[62] Phromnoi, K.; Yodkeeree, S.; Anuchapreeda, S.; Limtrakul, P. Inhibition of MMP-3 activity and invasion of the MDAMB-231 human invasive breast carcinoma cell line by bioflavonoids. Acta Pharmacol. Sin., 2009, 30, 1169-1176.

[63] Camargo, C. A.; da Silva, M. E. F.; da Silva, R. A.; Justo, G. Z.; Gomes-Marcondes, M. C. C.; Aoyama, H. Inhibition of tumor growth by quercetin with increase of survival and prevention of cachexia in Walker 256 tumor-bearing rats. Biochem. Biophys. Res. Commun., 2011, 406, 638-642.

[64] Lai, W. W.; Hsu, S. C.; Chueh, F. S.; Chen, Y. Y.; Yang, J. S.; Lin, J. P.; Lien, J. C.; Tsai, C. H.; Chung, J. G. Quercetin inhibits migration and invasion of SAS human oral cancer cells through inhibition of NF- $\mathrm{KB}$ and matrix metalloproteinase-2/-9 signaling pathways. Anticancer Res., 2013, 33, 1941-1950.

[65] Cao, H. H.; Tse, A. K. W.; Kwan, H. Y.; Yu, H.; Cheng, C. Y.; Su, T.; Fong, W. F.; Yu, Z. L. Quercetin exerts antimelanoma activities and inhibits STAT3 signaling. Biochem. Pharmacol., 2014, 87, 424-434.

[66] Pratheeshkumar, P.; Budhraja, A.; Son, Y. O.; Wang, X.; Zhang, Z.; Ding, S.; Wang, L.; Hitron, A.; Lee, J. C.; Xu, M.; Chen, G.; Luo, J.; Sin, X. Quercetin inhibits angiogenesis mediated human prostate tumor growth by targeting VEGFR- 2 regulated AKT/mTOR/P70S6K signaling pathways. PLoS One, 2012, 7, e47516.

[67] Anand, K.; Asthana, P.; Kumar, A.; Ambasta, R. K. Quercetin mediated reduction of angiogenic markers and chaperones in DLA-induced solid tumours. Asian Pac. J. Cancer Prev., 2011, 12, 2829-2835. 
[68] Kong, L.; Wu, K.; Lin, H. Inhibitory effects of quercetin on angiogenesis of experimental mammary carcinoma. Chin. J. Clin. Oncol., 2005, 2, 631-636.

[69] Long, Q.; Xiel, Y.; Huang, Y.; Wu, Q.; Zhang, H.; Xiong, S.; Liu, Y.; Chen, L.; Wey, Y.; Zhao, X.; Gong, C. Induction of apoptosis and inhibition of angiogenesis by PEGylated liposomal quercetin in both cisplatin-sensitive and cisplatin-resistant ovarian cancers. J. Biomed. Nanotechnol., 2013, 9, 965-975.

[70] Zhao, D.; Qin, C.; Fan, X.; Li, Y.; Gu, B. Inhibitory effects of quercetin on angiogenesis in larval zebrafish and human umbilical vein endothelial cells. Eur. J. Pharmacol., 2014, 723, 360-367.

[71] Furuta, H. E.; Okuda, A.; Kobayashi, K. W. Metabolic genes in cancer: their roles in tumor progression and clinical implications. Biochim. Biophys. Acta, 2010, 1805, 141152.

[72] Hanahan, D.; Weinberg, R. A.; Francisco, S. The hallmarks of cancer review university of california at san francisco. Cell, 2000, 100, 57-70.

[73] Hanahan, D.; Weinberg, R. A. Hallmarks of cancer: the next generation. Cell, 2011, 144, 646-674.

[74] Chou, T. Theoretical basis, experimental design, and computerized simulation of synergism and antagonism in drug combination studies. Pharmacol. Rev., 2007, 58, 621-681.

[75] Wang, G.; Zhang, J.; Liu, L.; Sharma, S.; Dong, Q. Quercetin potentiates doxorubicin mediated antitumor effects against liver cancer through p53/Bcl-xl. PLoS One, 2012, 7, e51764.

[76] Du, G.; Lin, H.; Wang, M.; Zhang, S.; Wu, X.; Lu, L.; Ji, L.; yu, L. Quercetin greatly improved therapeutic index of doxorubicin against 4T1 breast cancer by its opposing effects on HIF-1 $\alpha$ in tumor and normal cells. Cancer Chemother. Pharmacol., 2010, 65, 277-287.

[77] Temesgen, S.; Fadlalla, K.; Mosley, L.; Katkoori, V.; Turner, T.; Manne, U. Dual-mode interaction between quercetin and DNA-damaging drugs in cancer cells. AntiCancer Res., 2012, 32, 61-71.

[78] Xavier, C. P. R.; Lima, C. F.; Rohde, M.; Pereira-Wilson, C. Quercetin enhances 5-fluorouracil-induced apoptosis in MSI colorectal cancer cells through p53 modulation. Cancer Chemother. Pharmacol., 2011, 68, 1449-1457.

[79] Chuang-Xin, L.; Wen-Yu, W.; Yao, C.; Xiao-Yan, L.; Yun, $Z$. Quercetin enhances the effects of 5-fluorouracilmediated growth inhibition and apoptosis of esophageal cancer cells by inhibiting NF-кB. Oncol. Lett., 2012, 4, 775-778.

[80] Daker, M.; Ahmad, M.; Khoo, A. S. Quercetin-induced inhibition and synergistic activity with cisplatin - a chemotherapeutic strategy for nasopharyngeal carcinoma cells. Cancer Cell. Int., 2012, 12, 34-41.

[81] Zhao, J.; Zhao, J.; Jiao, H. Synergistic growth-suppressive effects of quercetin and cisplatin on HepG2 human hepatocellular carcinoma cells. Appl. Biochem. Biotechnol., 2014, 172, 784-791.

[82] Kuhar, M.; Sen, S.; Singh, N. Role of mitochondria in quercetin-enhanced chemotherapeutic response in human nonsmall cell lung carcinoma H-520 cells. Anticancer, 2006, 26, 1297-1304.

[83] Nessa, M. U.; Beale, P.; Chan, C.; Yu, J. Q.; Huq, F. Synergism from combinations of cisplatin and oxaliplatin with quercetin and thymoquinone in human ovarian tumour models. Anticancer Res., 2011, 3798, 3789-3797.

[84] Thangasamy, T.; Sittadjody, S.; Mitchell, G. C.; Mendonza, E. E.; Radhakrishnan, V. M.; Limesand, K. H.; Brud, R.
Quercetin abrogates chemoresistance in melanoma cells by modulating deltaNp73. BMC Cancer, 2010, 10, 1-10.

[85] Borska, S.; Sopel, M.; Chmielewska, M.; Zabel, M.; Dziegiel, P. Quercetin as a potential modulator of Pglycoprotein expression and function in cells of human pancreatic carcinoma line resistant to daunorubicin. Molecules, 2010, 15, 857-870.

[86] Sliutzl, G.; Karlseder, J.; Tempfer, C.; Orel, L.; Holzer, G.; Simon, M. M. Drug resistance against gemcitabine and topotecan mediated by constitutive hsp7O overexpression in. vitro : implication of quercetin as sensitiser in chemotherapy. Br. J. Cancer, 1996, 74, 172-177.

[87] Li, J.; Zhu, F.; Lubet, R. A.; De Luca, A.; Grubbs, C.; Ericson, M. E.; D’Alessio, A.; Normanno, N.; Dong, Z.; Bode, A. M. Quercetin-3-methyl ether inhibits lapatinib-sensitive and - resistant breast cancer cell growth by inducing G2/ arrest and apoptosis. Mol. Carcinog., 2014, 52, 134-143.

[88] Jakubowicz-Gil, J.; Langner, E.; Badziul, D.; Wertel, I.; Rzeski, W. Quercetin and sorafenib as a novel and effective couple in programmed cell death induction in human gliomas. Neurotox. Res., 2014, 26, 64-77.

[89] Kavithaa, K.; Sumathi, S.; Paulpandi, M.; Padma, P. R. Increased anticancer efficacy by the combined administration of quercetin in multidrug resistant breast cancer cells. BMR Cancer Res., 2014, 1, 1-13.

[90] Chan, S-T.; Yang, N-C.; Huang, C-S.; Liao, J-W.; Yeh, SL. Quercetin enhances the antitumor activity of trichostatin A through upregulation of $\mathrm{p} 53$ protein expression in. vitro and in vivo. PLoS One, 2013, 8, e54255.

[91] Gottesman, M. M.; Fojo, T.; Bates, S. E. Multidrug resistance in cancer: role of ATP-dependent transporters. Nat. Rev. Cancer, 2002, 2, 48-58.

[92] Casalta-lopes, J.; Abrantes, A. M.; Laranjo, M.; Rio, J.; Gonçalves, A. C.; Oliveiros, B.; Sarmento-Ribeiro, A. B.; Botelho, M. F. Efflux pumps modulation in colorectal adenocarcinoma cell lines: the role of nuclear medicine. $J$. Cancer Ther., 2011, 2, 408-417.

[93] Bussa, S.; Rumi, C.; Cianfriglia, M.; Mancuso, S. Quercetin potentiates the effect of Adriamycin in a multidrug-resistant MCF-7 human breast-cancer cell line: P-glycoprotein as a possible target. Cancer Chemother. Pharmacol., 1994, 34, 459-464.

[94] Sang, D.; Li, R.; Lan, Q. Quercetin sensitizes human glioblastoma cells to temozolomide in vitro via inhibition of Hsp27. Acta. Pharmacol. Sin., 2014, 35, 832-838.

[95] Azevedo, M. I.; Pereira, A. F.; Nogueira, R. B.; Rolim, F. E.; Brito, G. A.; Wong, D. V.; Lima-Júnior, R. C.; Ribeiro, R. A. R.; Vale, M. L. The antioxidant effects of the flavonoids rutin and quercetin inhibit oxaliplatininduced chronic painful peripheral neuropathy. Mol. Pain, 2013, 9, 53.

[96] Chen, J.; Hu, R.; Chou, H. Quercetin-induced cardioprotection against doxorubicin cytoxicity. J. Biomed. Sci., 2013, 20,2-10.

[97] Dong, Q.; Chen, L.; Lu, Q.; Sharma, S.; Li, L.; Morimoto, S.; Wang, G. Quercetin attenuates doxorubicin cardiotoxicity by modulating Bmi-1 expression. Br. J. Pharmacol., 2014, 171, 4440-4454.

[98] Priego, S.; Feddi, F.; Ferrer, P.; Mena, S.; Benlloch, M.; Ortega, A.; Carretero, J.; Obrador, E.; Asensi, M.; Estrela, J. M. Natural polyphenols facilitate elimination of HT-29 colorectal cancer xenografts by chemoradiotherapy: a Bcl2- and superoxide dismutase 2-dependent mechanism. Mol. Cancer Ther., 2008, 7, 3330-3342.

[99] Pozsgai, E.; Bellyei, S.; Cseh, A.; Boronkai, A.; Racz, B.; Szabo, A.; Sumegi, B.; Hocsak, E. Quercetin increases the 
efficacy of glioblastoma treatment compared to standard chemoradiotherapy by the suppression of PI-3-kinase-Akt pathway. Nutr. Cancer, 2013, 65, 1059-66.

[100] Varadkar, P.; Dubey, P.; Krishna, M.; Verma, N. C. Modulation of radiation-induced protein kinase $\mathrm{C}$ activity by phenolics. J. Radiol. Prot., 2001, 21, 361-370.

[101] Lin, C.; Yu, Y.; Zhao, H. G.; Yang, A.; Yan, H.; Cui, Y. Combination of quercetin with radiotherapy enhances tumor radiosensitivity in vitro and in vivo. Radiother. Oncol., 2012, 104, 395-400.

[102] van Rijn, J.; van den Berg, J. Flavonoids as enhancers of Xray-induced cell damage in hepatoma cells. Clin. Cancer Res., 1997, 3, 1775-1779.

Received: March 16, 2015

Revised: June 29, 2015

Accepted: August 05, 2015
[103] Horton, J. A.; Li, F.; Chung, E. J.; Hudak, K.; White, A.; Krausz, K.; Gonzalez, F.; Citrin, D. Quercetin inhibits radiation-induced skin fibrosis. Radiat. Res., 2013, 180, 205-215.

[104] Das, D. K. R.; Chakraborty, A.; Sinha, M.; Manna, K.; Mukherjee, D.; Chakraborty, A.; Bhattacharjee, S.; Dey, S. Modulatory role of quercetin against gamma radiationmediated biochemical and morphological alterations of red blood cells. Int. J. Radiat. Biol., 2013, 89, 471-481.

[105] Orsolic, N.; Benkovic, V.; Horvat-Knezevic, A.; Kopjar, N.; Kosalec, I.; Bakmaz, M.; Mihaljevic, Z.; Bendelja, K.; Basic, I. Assessment by survival analysis of the radioprotective properties of propolis and its polyphenolic compounds. Biol. Pharm. Bull., 2007, 30, 946-951. 